Review

\title{
Astrocytes Store for Memory and Cognition
}

\author{
Majid Karimi Baghmaleki \\ Private Practice, Isfahan, Iran
}

\section{Article history}

Received: 22-01-2021

Revised: 04-04-2021

Accepted: 09-04-2021

Email:m.karimi46@mail.mui.ac.ir

\begin{abstract}
In humans, protoplasmic astrocytes are found with high density in the cortex and hippocampus (both parts responsible for memory and cognition) and each astrocyte is in contact with two million of synapses. Astrocytes are responsible for the synaptogenesis and the removal of synapses, which is the basis of learning and memory. The synaptogenesis increases sevenfold with the addition of astrocytes to the neuronal culture media. Astrocytes divide the brain and spinal cord into separate domains, including neurons, synaptic terminals and blood vessels and are integrated by protoplasmic astrocytic appendages. Astrocytes are also responsible for the formation of a single, wide lattice called the syncytium, which can store and process a high volume of information and transmit voluminous messages through intracellular gap junctions. It is relatively slow and is in turn a reason for thinking and gradual use of the information stored in memory. Astrocytes are mainly involved in the intercellular diffusion of calcium signals and the tripartite synapses of neurons and astrocytes are more in the gray matter; in most cases, the astrocyte membrane completely covers the pre-synaptic and postsynaptic ends. Similar to neurons, astrocytes also exhibit cellular memory and connect and integrate with neurons both homocellularly and heterocellularly. New circuits are formed far from the damaged site with the degeneration of brain tissues, the brain adaptation process and replacement of astrocytes and long-term memory is preserved with the cooperation of astrocytes close to the lesion site. Cognitive decline is evident in aging and research shows that there is no obvious neuronal death while the death of astrocytes is evident in aging. The volume of astroglia cells decreases in schizophrenia, which is accompanied by impaired limen and cognition and radiotherapy of glioma causes disorders and reduces cognition and memory. In Alzheimer's, the hippocampus is destroyed together with thinning the site of contact with the anterior cortex of the forehead (brain scans).
\end{abstract}

Keywords: Astrocytes, Gap Junctions, $\mathrm{Ca}^{2+}$, Memory, Cognition, Learning, Syncytium, Volumetric Transfer, Tripartite Synapses, Astrogliosis, Neuron, Cortex, Blood-Brain Barrier, Glioma

\section{Introduction}

With the presentation of neural theory by Professor Santiago Ramon Cachal et al. for more than a century, the world of science believes that the efficiency of the nervous system and cognitive processes, as well as the structure and storage of memory, are mainly related to the activity and presence of neurons. In addition to extensive studies over the years, I have dreamed since childhood and have always been keen on the brain structure. I analyzed available information, discovered a logical relationship and introduced astroglia (mainly protoplasmic astrocytes and, to a lesser extent, interstitial astrocytes) despite the inability of human beings to discover small facts and the limitation of the possibility of studies with complete and convincing reasons for the storage of memory and actions. I believe that neurons play a role in the fast and instantaneous transfer of information stored in astrocytes. I hope technical professors take account of this fact in the scientific centers of the world.

\section{Discussion}

As the most numerous brain cells (90\%), astroglia are actually the basic elements that generate neurons and control the growth, activity and death of neuronal circuits 
individually. Astroglia form a functional syncytium and are interconnected through gap junctions, which are in fact a complete intracellular communication pathway. It allows the direct movement of ions, metabolic factors and secondary messengers throughout the central nervous system (brain) and is a reliable means to exchange information. Each astrocyte pair in the cortex is interconnected on average by 230 gap junctions. Binary coding of electrical communication in neural networks is a specialized method for the rapid transmission of information. However, neurons appear to be under the control of glia. Neurotransmitter receptors and ion channels on the glia are functional and it is now known that neuronal activity causes the membrane or cytosolic flow of calcium signals in the glial cells that have a synaptic connection with the neurons. Glia can send the signal back to neurons where they are able to secrete neurotransmitters, such as glutamate and ATP. This indicates that there are close connection and interaction between the two neuronal and glial circuits, which can intercommunicate through electrical and chemical synapses. In astrocytes, neurotransmitters can be released through the vesicular or non-vesicular pathway, or the extracellular fluid and act on adjacent cells. The released gas transmitters, such as nitric oxide, act by transmitting volumetric messages through diffusion into the extracellular and intracellular space of syncytial cell networks. In contrast, fast (cable) transmission is a slow volumetric transfer from a few seconds to a few minutes and even hours, which is directly related to the storage of information in memory and cognitive abilities. Such transmissions occur through gap junctions and the secondary messengers are mainly calcium ions in this transmission mode. Protoplasmic astrocytes are located in the gray matter (cortex) and hippocampus (the site of cognitive activity and memory). On the other hand, interlaminar astrocytes exist only in the cortex of higher primates, with a density of $10,000-30,000 / \mathrm{mm}^{3}$ and the total surface area of their appendages may reach $80,000 \mu \mathrm{m}^{2}$, covering practically all available neuronal membranes. The human brain has the highest glia/neuron ratio (1/1.65) among all species. Each human protoplasmic astrocyte contacts about two million synapses and covers them with its appendages. Surprisingly, the appendages of protoplasmic astrocytes and the size of the terminal mass were large in Albert Einstein's brain. Instead, interlaminar astrocytes are significantly reduced in Down syndrome and Alzheimer's disease. Blockage of gap junctions by volatile anesthetic gases, such as halothane and several alcohols (octanol or heptanol) is another indication of the proposed function of astrocytes. The tripartite synapse, which consists of three parts, the presynaptic end, the neuronal postsynaptic membrane and surrounded by astrocytes, exchanges information between neurons and astrocytes. There are also direct synaptic connections between the neuronal end and astrocytes in the hippocampus. Stimulation of neurons or neuronal afferents triggers $\mathrm{CA}^{2+}$ signaling in astrocytes of culture medium and brain sections in situ. Astroglia cells can detect the intensity of neuronal activity. Calcium fluctuations in astroglia are induced by neuronal stimulation and encoded by the frequency. Similar to neurons, astrocytes express cellular memory. Calcium signaling in astrocytes occurs spontaneously following thinking or responding to adjacent neuronal activity. $\mathrm{CA}^{2+}$ fluctuations in the glia are transmitted through the astroglia network, which can release neurotransmitters in sites far from the initial neuron-glia contact, thereby allowing the parallel expansion of information in the gray matter. Synapses are continuously appeared, strengthened, weakened, or die by astrocytes. This process is the basis of brain adaptation and represents what is known as the basis of memory and learning. Protoplasmic astrocytes in the gray matter divide the cortex into separate domains. The survival of most astrocytes in the hippocampus after $10 \mathrm{~min}$ ischemia is a reason for the post-stroke stability of memory. There is no obvious neuronal death in aging, but glycolysis increases quite evidently and there is evidence that astrocyte numbers increase up to 20-fold in older people with high cognitive efficiency and memory. Glioma radiation therapy often leads to decreased cognition and memory. Astrocytes also decrease in schizophrenia, bipolar patients and depression disorders. The hippocampus is destroyed in Alzheimer's, along with thinning the site of contact with the anterior cortex to the hippocampus (brain scans).

\section{Conclusion}

The introduction of astrocytes as sources of memory storage and the sites for cognitive processes (thinking, learning, sensation, logic, etc.) can be the beginning of new studies with a new approach and assumption, being of interest to scientists in this field of research. Hopefully, it is a great step towards opening one of the greatest human secrets with the possibility of studies in the field of neuroscience.

\section{Statement of Importance}

Changes in insight into the location of memory storage and cognition will generally lead to a change in the direction of future studies, resulting in more accurate results and many help to the relevant patients.

\section{Remarks}

Due to the limited volume of the article and, on the other hand, the continuous repetition of subjects in different references by different methods, it is not possible to mention the citation in the text of the article. 


\section{Method}

My research method is based on content analysis.

\section{Ethical Statement}

This article is original and contains unpublished material. The corresponding author confirms that all of the other authors have read and approved the manuscript and no ethical issues involved.

\section{References}

Agnati, L. F., Zoli, M., Strömberg, I., \& Fuxe, K. (1995). Intercellular communication in the brain: wiring versus volume transmission. Neuroscience, 69(3), 711-726. 4522(95)00308-6

Allen, N. J., \& Barres, B. A. (2005). Signaling between glia and neurons: focus on synaptic plasticity. Current opinion in neurobiology, 15(5), 542-548. https://doi.org/10.1016/j.conb.2005.08.006

Andrizen, L. (1903). The neuroglia elements in the human brain. BMJ 29, 227-230. https://doi.org/10.1136/bmj.2.1700.227

Araque, A., Parpura, V., Sanzgiri, R. P., \& Haydon, P. G. (1999). Tripartite synapses: glia, the unacknowledged partner. Trends in neurosciences, 22(5), 208-215. https://doi.org/10.1016/S0166-2236(98)01349-6

Auld, D. S., \& Robitaille, R. (2003). Glial cells and neurotransmission: an inclusive view of synaptic function. Neuron, 40(2), 389-400. https://doi.org/10.1016/S0896-6273(03)00607-X

Bennett, M. V., Contreras, J. E., Bukauskas, F. F., \& Sáez, J. C. (2003). New roles for astrocytes: gap junction hemichannels have something to communicate. Trends in neurosciences, 26(11), 610-617. https://doi.org/10.1016/j.tins.2003.09.008

Berger, T., Schnitzer, J., Orkand, P. M., \& Kettenmann, H. (1992). Sodium and calcium currents in glial cells of the mouse corpus callosum slice. European Journal of Neuroscience, 4(12), 1271-1284. https://doi.org/10.1111/j.1460-9568.1992.tb00153.x

Bloom, F. E. (2000). Integration of wiring transmission and volume transmission. Progress in brain research, 125, 21-26. https://doi.org/10.1016/S00796123(00)25004-8

Colombo, J. A., \& Reisin, H. D. (2004). Interlaminar astroglia of the cerebral cortex: a marker of the primate brain. Brain research, 1006(1), 126-131. https://doi.org/10.1016/j.brainres.2004.02.003

Colombo, J. A., Reisin, H. D., Miguel-Hidalgo, J. J., \& Rajkowska, G. (2006). Cerebral cortex astroglia and the brain of a genius: A propos of A. Einstein's. Brain research reviews, 52(2), 257-263. https://doi.org/10.1016/j.brainresrev.2006.03.002
Cornell-Bell, A. H., Finkbeiner, S. M., Cooper, M. S., \& Smith, S. J. (1990). Glutamate induces calcium waves in cultured astrocytes: long-range glial signaling. Science, 247(4941), 470-473. https://doi.org/10.1126/science.1967852

Dermietzel, R. (1998). Gap junction wiring: pllpanew'principle in cell-to-cell communication in the nervous system?. Brain Research Reviews, 26(2-3), 176-183. https://doi.org/10.1016/S01650173(97)00031-3

Evans, W. H., De Vuyst, E., \& Leybaert, L. (2006). The gap junction cellular internet: connexin hemichannels enter the signalling limelight. Biochemical Journal, 397(1), 1-14. https://doi.org/10.1042/BJ20060175

Fields, R. D., \& Burnstock, G. (2006). Purinergic signalling in neuron-glia interactions. Nature Reviews Neuroscience, 7(6), 423-436. https://doi.org/10.1038/nrn1928

Haydon, P. G. (2001). GLIA: listening and talking to the synapse. Nature Reviews Neuroscience, 2(3), 185-193. https://doi.org/10.1038/35058528

Jabs, R., Pivneva, T., Hüttmann, K., Wyczynski, A., Nolte, C., Kettenmann, H., \& Steinhäuser, C. (2005). Synaptic transmission onto hippocampal glial cells with hGFAP promoter activity. Journal of cell science, 118(16), 3791-3803. https://doi.org/10.1242/jcs.02515

Kettenmann, H.,\& Ransom, B. R. (2004). Neuroglia. Oxford University Press, 2st edition.https://doi.org/10.1093/acprof:oso/97801951 52227.001.0001

Kuffler, S. W., \& Potter, D. D. (1964). Glia in the leech central nervous system: physiological properties and neuron-glia relationship. Journal of Neurophysiology, 27(2), 290-320. https://doi.org/10.1152/jn.1964.27.2.290

Lin, J. H., Weigel, H., Cotrina, M. L., Liu, S., Bueno, E., Hansen, A. J., ... \& Nedergaard, M. (1998). Gapjunction-mediated propagation and amplification of cell injury. Nature neuroscience, 1(6), 494-500. https://doi.org/10.1038/2210

Lin, S. C., \& Bergles, D. E. (2004). Synaptic signaling between neurons and glia. Glia, 47(3), 290-298. https://doi.org/10.1002/glia.20060

MacVicar, B. A. (1984). Voltage-dependent calcium channels in glial cells. Science, 226(4680), 1345-1347. https://doi.org/10.1126/science.6095454

Magistretti, P. J., \& Pellerin, L. (2000). The astrocytemediated coupling between synaptic activity and energy metabolism operates through volume transmission. Progress in brain research, 125, 229-240. https://doi.org/10.1016/S0079-6123(00)25013-9

Martins-Ferreira, H., Nedergaard, M., \& Nicholson, C. (2000). Perspectives on spreading depression. Brain research reviews, 32(1), 215-234. https://doi.org/10.1016/S0165-0173(99)00083-1 
Mcferrin, M. B., \& Sontheimer, H. (2006). A role for ion channels in glioma cell invasion. Neuron glia biology, 2(1), 39. https://doi.org/10.1017/S1740925X06000044

Mitterauer, B. (2004). Imbalance of glial-neuronal interaction in synapses: a possible mechanism of the pathophysiology of bipolar disorder. The Neuroscientist, 10(3), 199-206. https://doi.org/10.1177/107385403262248

Nagele, R. G., Wegiel, J., Venkataraman, V., Imaki, H., Wang, K. C., \& Wegiel, J. (2004). Contribution of glial cells to the development of amyloid plaques in Alzheimer's disease. Neurobiology of aging, 25(5), 663-674. https://doi.org/10.1016/j.neurobiolaging.2004.01.007

Nedergaard, M., \& Dirnagl, U. (2005). Role of glial cells in cerebral ischemia. Glia, 50(4), 281-286. https://doi.org/10.1002/glia.20205

Newman, E. A., \& Zahs, K. R. (1997). Calcium waves in retinal glial cells. Science, 275(5301), 844-847. https://doi.org/10.1126/science.275.5301.844

Oberheim, N. A., Wang, X., Goldman, S., \& Nedergaard, M. (2006). Astrocytic complexity distinguishes the human brain. Trends in neurosciences, 29(10), 547-553. https://doi.org/10.1016/j.tins.2006.08.004

Orkand, R. K., Nicholls, J. G., \& Kuffler, S. W. (1966). Effect of nerve impulses on the membrane potential of glial cells in the central nervous system of amphibia. Journal of neurophysiology, 29(4), 788-806. https://doi.org/10.1152/jn.1966.29.4.788

Pascual, O., Casper, K. B., Kubera, C., Zhang, J., Revilla-Sanchez, R., Sul, J. Y., ... \& Haydon, P. G. (2005). Astrocytic purinergic signaling coordinates synaptic networks. Science, 310(5745), 113-116. https://doi.org/10.1126/science.1116916

Sherwood, C. C., Stimpson, C. D., Raghanti, M. A., Wildman, D. E., Uddin, M., Grossman, L. I., ... \& Hof, P. R. (2006). Evolution of increased glianeuron ratios in the human frontal cortex. Proceedings of the National Academy of Sciences, 103(37), 13606-13611. https://doi.org/10.1073/pnas.0605843103

Retzius GM (1881-1921). Biologische Untersuchungen, vol. 1-6 Samson and Willin, Stockholm First theory of active neuronal -glial interactions. https://doi.org/10.5962/bhl.title.168154
Sáez, J. C., Retamal, M. A., Basilio, D., Bukauskas, F. F., \& Bennett, M. V. (2005). Connexin-based gap junction hemichannels: gating mechanisms. Biochimica et Biophysica Acta (BBA)Biomembranes, 1711(2), 215-224. https://doi.org/10.1016/j.bbamem.2005.01.014

Sosinsky, G. E., \& Nicholson, B. J. (2005). Structural organization of gap junction channels. Biochimica et Biophysica Acta (BBA)-Biomembranes, 1711(2), 99-125. https://doi.org/10.1016/j.bbamem.2005.04.001

Sykova, E. (2005). Glia and volume transmission during physiological and pathological states. Journal of neural transmission, 112(1), 137-147. https://doi.org/10.1007/s00702-004-0120-4

Verkhratsky, A. (2006). Patching the glia reveals the functional organisation of the brain. Pflügers Archiv, 453(3), 411-420. https://doi.org/10.1007/s00424-006-0099-9

Virchow, R. (1846). Über das granulierte Ansehen der Wandungen der Gerhirnventrikel. Allg Z Psychiatr, 3, 242.

Volterra, A., \& Steinhäuser, C. (2004). Glial modulation of synaptic transmission in the hippocampus. Glia, 47(3), 249-257.https://doi.org/10.1002/glia.20080

WALZ, W. (1997). Role of astrocytes in the spreading depression signal between ischemic core and penumbra. Neuroscience \& Biobehavioral Reviews, 21(2), 135-142. https://doi.org/10.1016/S01497634(96)00003-6

Walz, W., Klimaszewski, A., \& Paterson, I. A. (1993). Glial swelling in ischemia: a hypothesis. Developmental neuroscience, 15(3-5), 216-225. https://doi.org/10.1159/000111337

Wyss-Coray, T., Loike, J. D., Brionne, T. C., Lu, E., Anankov, R., Yan, F., ... \& Husemann, J. (2003). Adult mouse astrocytes degrade amyloid- $\beta$ in vitro and in situ. Nature medicine, 9(4), 453-457. https://doi.org/10.1038/nm838

Zoli, M., Torri, C., Ferrari, R., Jansson, A., Zini, I., Fuxe, K., \& Agnati, L. F. (1998). The emergence of the volume transmission concept. Brain Research Reviews, 26(2-3), 136-147. https://doi.org/10.1016/S0165-0173(97)00048-9 